\title{
Comparative Study between Mini Incision Open Appendectomy and Laparoscopic Appendectomy in Terms of Post Operative Pain Length of Hospital Stay and Return to Normal Life
}

\author{
Authors \\ Dr R.Sharanya ${ }^{1}$, Dr V. Shruthi Kamal ${ }^{2}$, Dr G. Parameswari ${ }^{3}$ \\ ${ }^{1}$ Senior Resident, Department of General Surgery, Saveetha Medical College Hospital, Thandalam \\ Ph 9884489870, Email: sharu_ravi@yahoo.com \\ ${ }^{2}$ Professor, Department of General Surgery, Saveetha Medical College Hospital, Thandalam \\ $\mathrm{Ph} 9840037030$ \\ ${ }^{3}$ Regional Joint Director, Department of higher education, Statistician, Coimbatore \\ Ph 9444290069, Email: raviparam2014@gmail.com
}

\begin{abstract}
To compare mini incision open appendectomy and laparoscopic appendectomy in terms of post operative pain length of hospital stay and return to normal life. 100 patients with appendicitis were randomized into mini incision appendectomy and laparoscopic appendectomy. As most of the patients in rural patients prefer early return to work and also have high tolerance to pain, this study emphasis the need for identifying the better procedure.

Although mini incision appendectomy also has small incision and similar hospital stay, laparoscopic surgery has emerged as the superior procedure in this population whose paramount interest is early return to work.

Keywords: acute appendicitis, mini incision appendectomy, laparoscopic appendectomy, early return to work, post operative pain.
\end{abstract}

\section{Introduction}

Vermiform appendix is a vestigial organ, as defined by most. However its importance in our lives is only due to its propensity for inflammation, which results in the condition called as acute appendicitis. The most common cause of an acute abdomen we routinely see in young adults in our daily practice is acute appendicitis with a lifetime incidence between 7 and $9 \%{ }^{1}$

Appendicitis is sufficiently common, so we perform a procedure namely appendectomy which means removal of the inflamed appendix.
Open appendectomy (OA) is performed through the right lower quadrant incision was first described in $1894^{2}$. It became the standard treatment of choice for acute appendicitis, remained unchanged for almost 100 years due to its efficacy and safety. Laparoscopic appendectomy (LA), first performed by Semm ${ }^{3}$ in 1983, has gradually gained acceptance.

The laparoscopic skill have evolved over the years with sophisticated articulating instruments in last few decades and has become favored over open surgical methods for its association with reduced postoperative pain, early return to daily activities, 
and better cosmetic results. However, the association of laparoscopy with specific adverse events such as increased intra-abdominal abscess, hospital costs and need for extensive special training also a time consuming procedure compared to open appendectomy ${ }^{4}$. So the need for this research is to assess the benefits of the better procedure for appendicitis in the rural working population. The mini-incision appendectomy (MOA) is performed in patients with non complicated acute appendicitis with a very small incision. The present study aimed to compare both laparoscopic and mini-incision appendectomies in terms of operation duration, postoperative complications, length of hospital stay and time taken to return to normal activity.

\section{Materials and Methods}

A prospective comparative study of 100 patients who were diagnosed with appendicitis and warranted surgery in Department of General Surgery conducted from April 2015 to August 2016.

\section{Inclusion criteria}

Patients diagnosed with appendicitis (Both emergencies and elective cases)

Age group between 18 to 60 years

Cases diagnosed by either ultra sonogram or by clinical examination

\section{Exclusion criteria}

Patients less than 18 years or more than 60 years

Appendicitis with other appendicular pathologies like
i) Appendicular abscess
ii) Appendicular mass
iii) Appendicular malignancy

Previous history of abdominal surgeries

Patients who are not fit for general or spinal anesthesia

\section{Methodology and Research Design}

It is a prospective comparative study

100 patients were included in this study, splitting them into two groups MOA and LA.

A detailed history of the patients was taken, and physical examination, complete blood analysis, urine examination and ultrasound of the abdomen was routinely performed in all the cases. The patients were explained about the risks and the benefits of the two procedures and their informed consent were obtained. All the 100 patients included in this study, splitting them into two groups LA and MOA by simple randomization.

Patients received $1 \mathrm{~g}$ of cefotaxime and $500 \mathrm{mg}$ of metronidazole every 12 hours and every 8 hours respectively intravenously from the time of diagnosis until surgery. If the patients found to have a complicated appendicitis with perforation or gangrene during surgery were treated with cefoperazone $1 \mathrm{gm}$ and sulbactum $500 \mathrm{mg}$ every 12 hours in addition to $500 \mathrm{mg}$ metronidazole. All patients received antibiotics postoperatively upto third post op day.

\section{Surgery}

\section{Laparoscopic Appendectomy}

Experienced surgeons performed all operations with senior residents. LA was performed using 3 ports, with $10 \mathrm{~mm}$ port with laparoscope positioned at the umbilicus. Two $5 \mathrm{~mm}$ ports were inserted in the right and left lower quadrants. In the abdominal cavity the appendix was identified and other pathology were ruled out. The appendix and the mesoappendix were divided. The appendix was removed in a laparoscopic bag. Fascial defects in the port sites were closed using 1 Vicryl suture. The skin incisions were closed in every case using 3-0 ethilon. All the operative details were recorded.

\section{MINI Incision Appendecectomy}

A 2.5 to $3 \mathrm{~cm}$ incision was made at the lateral border of the right rectus muscle at the $\mathrm{Mc}$ Burney's point and deepened, Rectus muscles were retraced medially and underlying layers were incised entered into the peritoneal cavity. Appendecectomy was done similarly and closed in layers with 2-0 vicryl and skin wit 3-0 ethilon. The patients were kept nil per oral till the return of the bowel sounds. A soft diet, followed by regular diet, was introduced when the patients tolerates the liquid diet and has passed flatus. 


\section{Outcome Parameters}

The following parameters were recorded:

\section{A) Postoperative pain}

It was assessed in by the data collector qualitatively using a visual linear Scale (visual analogue scale) the severity of the worst pain that they experienced in the preceding 24 hours. The item was scaled from 0 to 10 , with 0 being no pain and 10 being the most intense pain imaginable. This was noted on POD 1, 3 and 7.

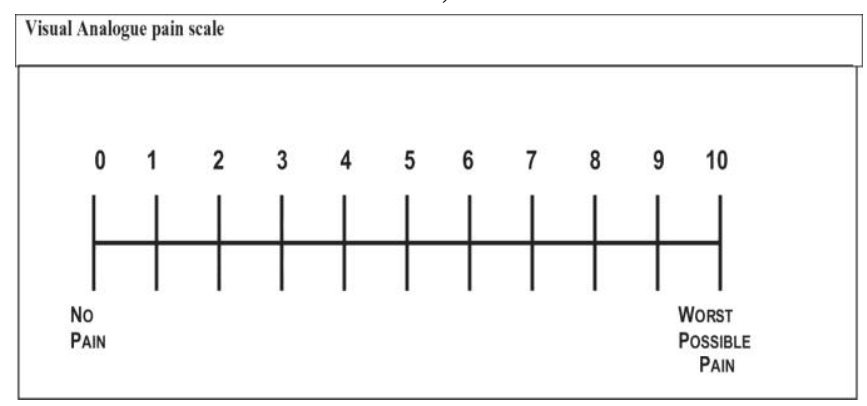

Figure 1 Visual analogue scale is used to quantify pain.
B) A 13-item Activity Assessment Scale was used to measure activity on every postoperative day. This measured the patient's ability to perform 13 activities: lying in bed, sitting, getting in or out of bed or chair, reaching or stretching activity, lifting 3 to 5 pounds, walking around inside, climbing up and down stairs, walking outside or at work, sedentary activities, light physical activities, moderate physical activities, vigorous activities, sexual activity. All items had response categories scaled from 1 through 5 , with verbal descriptors for each item. The response categories for activity were (1) no difficulty at all; (2) a little difficulty; (3) some difficulty; (4) a lot of difficulty; (5) not able to do it

Table - 1 Activity Assessment scale, used to asses activity that a post operative patient is able to do.

\begin{tabular}{|l|l|l|l|l|l|}
\hline & $\begin{array}{c}\text { no difficulty at } \\
\text { all; (1) }\end{array}$ & $\begin{array}{c}\text { (2) a little } \\
\text { difficulty; }\end{array}$ & $\begin{array}{c}\text { (3) some } \\
\text { difficulty; }\end{array}$ & $\begin{array}{c}\text { (4) a lot of } \\
\text { difficulty }\end{array}$ & $\begin{array}{c}\text { (5) not able to } \\
\text { do it. }\end{array}$ \\
\hline lying in bed & & & & & \\
\hline sitting & & & & & \\
\hline $\begin{array}{l}\text { getting } \\
\text { in or out of bed or chair }\end{array}$ & & & & & \\
\hline $\begin{array}{l}\text { reaching or stretching } \\
\text { activity }\end{array}$ & & & & & \\
\hline lifting 1 to 3 pounds & & & & & \\
\hline $\begin{array}{l}\text { walking around } \\
\text { inside }\end{array}$ & & & & & \\
\hline $\begin{array}{l}\text { climbing up and down } \\
\text { stairs }\end{array}$ & & & & & \\
\hline at work & & & & & \\
\hline sedentary activities & & & & & \\
\hline $\begin{array}{l}\text { light } \\
\text { physical activities }\end{array}$ & & & & & \\
\hline $\begin{array}{l}\text { Moderate } \\
\text { physical activities }\end{array}$ & & & & & \\
\hline $\begin{array}{l}\text { vigorous } \\
\text { physical activities }\end{array}$ & & & & & \\
\hline Sexual activity & & & & & \\
\hline
\end{tabular}

The Activity Assessment scale is the sum of the 13 items, with higher scores indicating poorer activity.

It was noted on POD 1, 3 and after 2 weeks in follow up.

C) Length of Hospital Stay. The length of hospital stay (measured in days) is defined as the difference between date of admission and date of discharge of the patient. Length of stay was coded as 0 for patients discharged during the day of admission.

Results for normally distributed continous variables were compared by student $t$-tests; and results for continous non-normally distributed 
variables were compared using a Mann Whitney $U$ test. Variables were considered statistically significant if the $P$-value $\leq 0.05$ was in the $95 \%$ CI.

\section{Results}

The study consists of 100 patients were randomly divided into two groups, MOA $(n=50)$ or LA $(n$ $=50$ ).

In this study out of hundred patients in this study, fifty five percent were males, in that sixty four percent of males underwent MOA whereas forty six percent underwent LA.
Forty five percent of the patients in the sample size were females, thirty six percent underwent MOA and fifty four percent underwent LA. Mean age group who underwent MOA is 30.16 and LA is 28.26 .

No patients had undergone conversion from LA to $\mathrm{OA}$, there were no statistical differences in demographics between the two groups. The mean operating time was similar in both groups. In postoperative VAS There is a significant difference between MOA and LA in POD 1,3 and 7 at ' $p$ value' $<0.001$ which is $99.9 \%$ statistically significant.

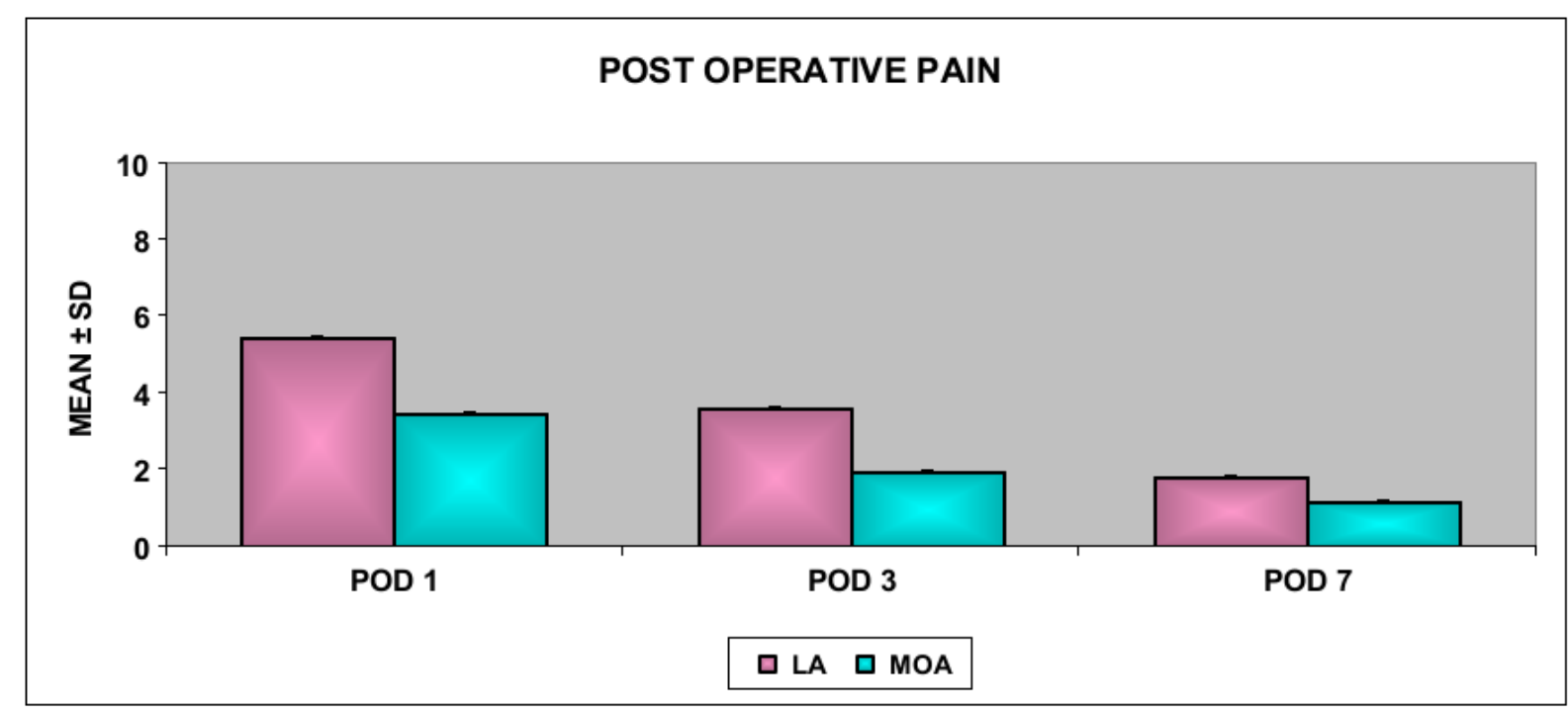

Figure 2 Comparison between the post operative pain in the test groups

The usage of analgesics in the LA group was significantly lower in the postoperative period $(P$ $<0.001)$.

The mean physical activity score for MOA and LA on POD1, POD 3 and after two weeks were 54.82 and 47.60; 49.18 and 44.60; 37.28 and 36.70 respectively.

There is significant difference between MOA and LA in POD 1 and 3 at ' $p$ value' $<0.001$, that is
99.9\% statistically significant, however during post op follow up at two weeks ' $p$ value' is 0.531 which is > than 0.05 hence at second week the results were comparable between the two groups and there was no significant difference, so earlier return to normal life was noted in LA. But not a much of difference in late post operative period. 


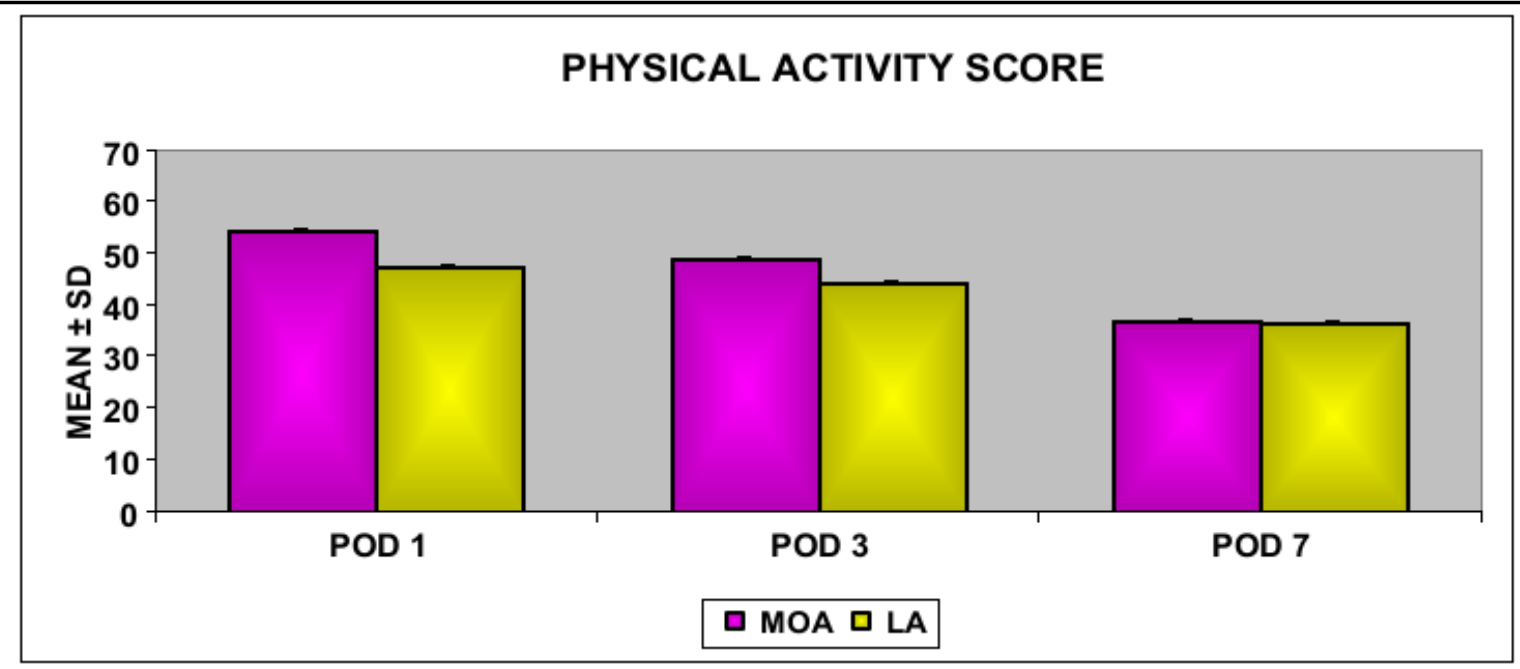

Figure 3 Comparison between the physical activity scores in the test groups

The mean length of hospital stay in M OA and LA it was only 4.30 days.

The length of hospital stay in LA and OA were both same and there was no difference hence was not statistically significant.

No mortality was reported in the follow-up period.

\section{HOSPITAL STAY IN DAYS}

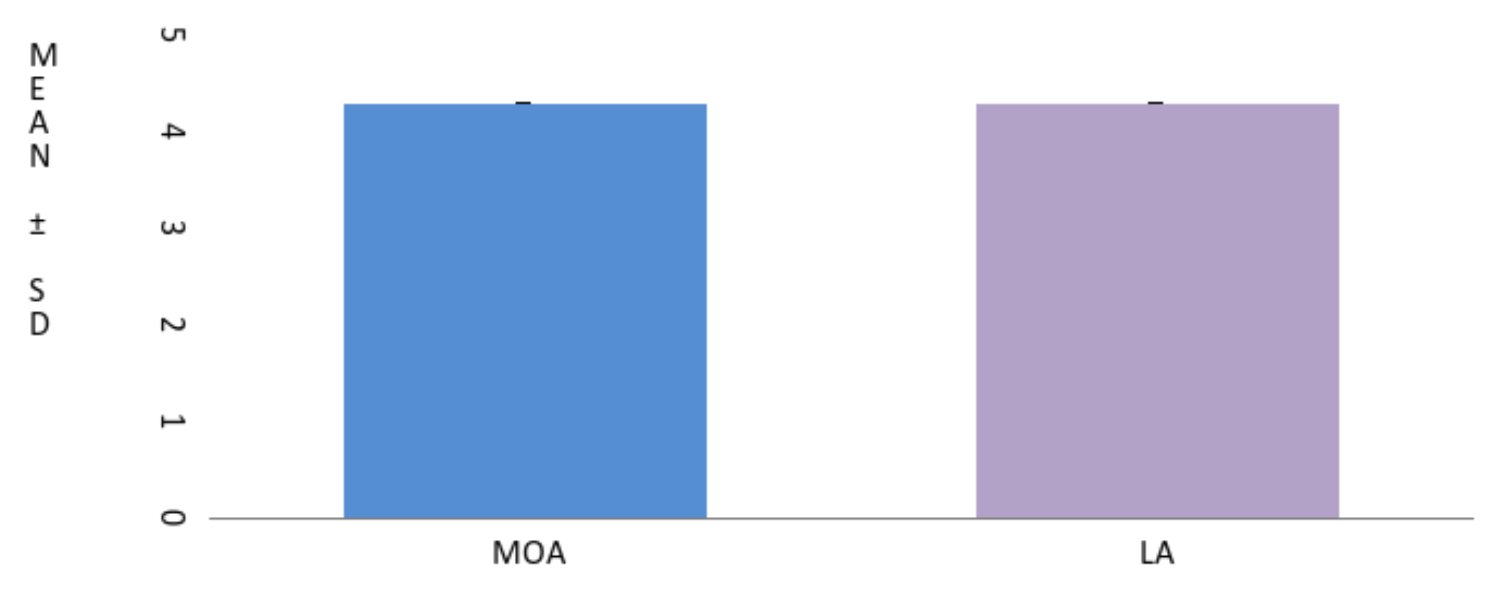

Figure 4 Comparison between the hospital stay in the test groups

\section{Discussion}

Various studies have been done between LA and MOA, however this study was conducted in the rural background where most of the patients have high pain tolerance, the early return to work is very important as most of them work for daily wages with length of hospital has significant impact on the economic dynamics of the family. Furthermore the incisions for MOA have reduced significantly and are comparable to the incisions in LA leading to lesser post op pain and early discharge.

Pain assessment was studied by the administration of a visual analogue scale test on POD 1,3 and 7 by using visual analogue scale. The mean pain score was 5.48 for MOA and 3.50 for LA on first POD, 3.60 and 1.98 respectively on POD 3; 1.80 and 1.18 respectively on POD 7 . There is a significant difference between MOA and LA in POD 1,3 and 7 at ' $p$ value' $<0.001$ which is $99.9 \%$ statistically significant. 
There was decreased post operative pain in LA in POD1, POD 3 and POD 7.

According to Chung $\mathrm{RS}^{5}$, there was significant reduction post op pain in patients who underwent LA and there was also decreased requirement of analgesia

But according to Mutter $\mathrm{L}^{6}$, he stated that there is no difference between the two groups and post op pain was comparable between them.

The return to activity or normal life following appendectomy is the subject of intense debates. By definition a minimally invasive operation (LA) should allow for a quicker recovery, shorter period of rest at home, and quicker return to work. Our results based on the use of an objective instrument to measure the activity showed The mean physical activity score for MOA and LA on POD1, POD 3 and after two weeks were 54.82 and $47.60 ; 49.18$ and 44.60; 37.28 and 36.70 respectively. There is significant difference between MOA and LA in POD 1 and 3 at ' $p$ value' $<0.001$, that is $99.9 \%$ statistically significant, however during post op follow up at two weeks ' $p$ value' is 0.531 which is $>$ than 0.05 hence at second week the results were comparable between the two groups and there was no significant difference.

In contrast, Ignacio et $\mathrm{al}^{7}$ carried out a blinded prospective study in a tertiary care military-based hospital on healthy active-duty men. This specific centre for study was selected because the mandatory documentation required for convalescence in the military made for accurate assessment of lost days. In this study, there was no difference in pain on days 1 and 7 postoperatively or in the time to return to work.

Kathoudha et $\mathrm{al}^{8}$ did a similar study and stated that both the procedures were comparable in terms of physical activity with no difference.

In terms of hospital stay, patients who underwent laparoscopic appendectomy had shorter stay compared to those who underwent open appendectomy. The mean length of hospital stay in MOA and LA were only 4.30 days, here there is no significant difference between MOA and LA in length of hospital stay.
However, our literature and previous studies prove the same. It is stated that length of hospital does not significantly vary between the procedures.

According to Faith ${ }^{9}$ there was no significant difference between MOA and LA, however.

According to Garbutt $\mathrm{JM}^{10}$, after meta-analyses of RCT there was difference between the two groups.

Bionidini $\mathrm{A}^{11}$ stated that there was decreased hospital stay which lead to earlier return to work.

This varying trends in length of hospital stay may be due to the varying social standards and insurance system according to various European studies $^{12,13,14}$.

Çiftçi $\mathrm{F}^{15}$ has done extensive work with mini incision open appendectomy with a $3 \mathrm{~cm}$ Mcburney's incision and compared it with LA. He has stated that the decrease in the length of incision has significantly impacted the outcome. In his study length of hospital stay and complications were significantly reduced and also concluded that it was an alternative procedure too LA in certain group of patients.

According Ozoin $\mathrm{I}^{16}$ he stated that mini-incision appendectomy seems to be an alternative for selected patients with lower body mass index and non complicated appendicitis.

Laparoscopic approach demonstrated decrease in post operative pain and ability to return to normal life with patients having no difficulty in doing daily activities in the immediate post operative period earlier than mini incision appendectomy.

\section{Conclusion}

Based on this study of mini incision appendectomy and laparoscopic appendectomy in terms of post op pain, length of hospital stay and return to normal life, I conclude that;

1. Post operative pain was significantly less in first and third post operative day for the patients who underwent laparoscopic appendectomy.

2. Length of hospital was almost same for the patients who underwent laparoscopic appendectomy and mini incision appendectomy. 
3. Early return to work was observed in patients who underwent laparoscopic appendectomy.

Hence laparoscopic appendectomy is a better procedure for appendicitis.

\section{Supports and grants - nil}

\section{References}

1. Addiss DG, Shaffer N, Fowler BS, Tauxe RV: The epidemiology of appendicitis and appendectomy in the United States. Am J Epidemiol. 1990, 132: 910-925. (PMID: 2239906)

2. McBurney $\mathrm{C}$ : The incision made in the abdominal wall in cases of appendicitis, with a description of a new method of operating. Ann Surg. 1894, 20: 38-43. 10.1097/00000658-189407000-00004. (PMID: 17860070)

3. Semm K: Endoscopic appendectomy. Endoscopy. 1983, 15: 59-64. 10.1055/s-20071021466. (PMID: 6221925)

4. Sauerland S., Lefering R., Neugebauer E. A. Laparoscopic versus open surgery for suspected appendicitis. Cochrane Database of Systematic Reviews. 2004;(4)CD001546

5 Chung RS, Rowland DY, Li P, et al. A metaanalysis of randomized controlled trials of laparoscopic versus conventional appendectomy. Am J Surg. 1999;177:250256. [PubMed]

6 Mutter D, Vix M, Bui A, et al. Laparoscopy not recommended for routine appendectomy in men: results of a prospective randomized study. Surgery. 1996;120:71-74. [PubMed]

7 Ignacio RC, Burke R, Spencer D, et al. Laparoscopic versus open appendectomy: what is the real difference? results of a prospective randomized double-blinded trial. Surg Endosc. 2004;18:334-337. [PubMed]

8 Katkhouda N, Friedlander MH, Grant SW, et al. Intraabdominal abscess rate after laparoscopic appendectomy. Am J Surg. 2000;180:456-459. [PubMed]
9 Fatih Çiftçi Laparoscopic vs mini-incision open appendectomy World J Gastrointest Surg. 2015 Oct 27; 7(10): 267-272

10 Garbutt $\mathrm{JM}^{1}$, Soper NJ, Shannon WD, Botero A, Littenberg BMeta-analysis Of randomized controlled trials comparing laparoscopic and open appendectomy. SurgLaparoscEndosc. 1999 Jan;9(1):17-26.

11 Biondini A Laparoscopic versus open appendectomy: a retrospective cohort study assessing outcomes and cost-effectiveness World J Emerg Surg. 2016; 11(1): 44.2016 Aug 30. doi: 10.1186/s13017-016-0102-5

12 Hellberg A, Rudberg C, Kullman E, et al. Prospective randomized multicentre study of laparoscopic versus open appendicectomy. $\mathrm{Br}$ J Surg. 1999;86:48 53. [PubMed]

13 Kazemier G, De Zeeuw GR, Lange JF, et al. Laparoscopic vs. open appendectomy: a randomized clinical trial. SurgEndosc. 1997;11:336-340. [PubMed]

14 Klingler A, Henle KP, Beller S, et al. Laparoscopic appendectomy does not change the incidence of postoperative infectious complications. Am J Surg. 1998;175:232235.

15 Çiftçi F Laparoscopic vs mini-incision open appendectomy. World J Gastrointest Surg. 2015 Oct 27;7(10):267-72. doi: 10.4240/wjgs.v7.i10.267.

16 İsmail Özsan, Türker Karabuğa, Ömer Yoldaş, Özcan Alpdoğan, and Ünal Aydın Laparoscopic Appendectomy versus MiniIncision Appendectomy in Patients with Lower Body Mass Index and Non complicated Appendicitis Gastroenterol Res Pract. 2014; 2014: 138648. Published online 2014 Dec 14. doi: 10.1155/2014/138648. 